\title{
Feedback
}

\section{HSM: Europe calling}

Actually, I have been preparing to write to you since Jean-Louis Le Moigne's feedback has been published entitled 'HSM in Europe' (vol. 1 (4) p. 348). At that time I decided to write another feedback on 'HSM in Eastern Europe', but later I changed my mind because I did not want to write in the name of the East-European scientific community interested in HSM related issues. However, I can assure you that we are interested in it, but we are in a different situation compared to that of the West-European scientists. Beyond the differences there are, in this respect, much more relevant similarities to what was very well described by our French colleague. I shall arrange my comments around his letter.

I share the view that we have difficulties to involve more (East) Europeans in $H S M$ activity. If there are difficulties in this respect, in France for instance, we even have them in an accumulated way.

We have a solid scientific activity in the systems related fields. During national meetings we also put the basic questions about the methodologies, during the $60 \mathrm{~s}$ in national OR conferences and in the 70s in systems conferences. We were received by the OR people in a way very similar to how Gene Woolsey had been during TIMS/ORSA meetings in the States (Woolsey, 1978). When we emphasized the pragmatic aspects of OR in addition to the syntactic and semantic ones they felt that we attacked a young scientific discipline and asked "why do you want to break your violin when you want to play music?". Unfortunately, our OR community has understood very slowly that music playing in this sense is not a solo performance but that of an orchestra where experts from different disciplines play their own instruments and harmony is the final aim. Later in the $70 \mathrm{~s}$ it seemed to us that systems theoretical

North-Holland

Human Systems Management 5 (1985) 81-82 thinking will give us a new frame for our broader, more integrative way of thinking. Since then, a new community has been emerging, which is more interested in the combined (hard and soft) methodologies than those interested only in toolmaking, where the tools are restricted to mathematical ones. After getting acquainted, this community started to look for interdisciplinary scientific contacts abroad in addition to the already existing traditional or disciplinary oriented ones. (I have to note here that international cooperation among OR people emerged for the first time among mathematicians and not operational researchers as such.)

We also have to consider that in our country(ies) the normative, prescriptive approach has had stronger traditions than the descriptive, soft-science oriented one and - or just because of this the way of thinking has been changing very slowly.

After a period of maturation we here in Hungary were also able to assess the same basic questions as you and your French colleagues did in America and in France respectively [1].

But you can observe similar problems in the case of the introduction of new methodologies and approaches if you consider what has happened at IIASA. There is a very definite but underground battle between the traditional - rather model-oriented - operations researchers and the problem oriented systems analysts, who try to think and work in a more interdisciplinary way. What happened with our "Rethinking...." seminar, organized with and the book edited by Professor Tomlinson and me, could be a good example of what kind of emotions appear when new ideas try to make a breakthrough.

In the field of decision theory a significant development is also observable in Hungary. First we organized a national workshop on decision making in 1980, overviewing the new methods developed elsewhere and the way we can facilitate their application in Hungary. Then, in 1981, we 
organized a seminar of East-European scientists on new methods of decision analysis that emphasized the multicriterion nature of decision problems, the methods how to consider preferences of groups and so on. In 1982 we hosted the 8th International Research Conference on Subjective Probability, Utility and Decision Making. By now we have an evaluation of application of these methods in Hungary and we manage a program to facilitate their application. Nowadays, our experts in these new fields become better known.

I really do not want to show off, but I had the intention to let you know what kind of process is taking place here. But I have the feeling that after internal debates and our participation in international discussions we shall be able to appear publicly through publications and we have some energy to organize further international cooperation. But there is still a difficulty - referred to by Le Moigne as well - that of translation. Compared to the French situation we cannot find a good 'bilingual student', so the translation is even more crucial in our case. I had experiences when a submitted paper from Hungary was rejected because of the translation, which could not appropriately reflect the idea of the author.

Summarizing, I would say that we have reached a certain level of maturation (which process took a rather long time as some disciplines were bourgeois pseudo-sciences until the late 50 s, so the development started again after approximately 10 years), we have motivation to be visible, audible and readable so I hope that we will be able to join cooperation in these new fields as well.

I support the idea to make $H S M$ more visible. I suggest submitting some information on HSM to the SGSR to be published in its Bulletin. SGSR does not cover a large community, but it is perhaps the forum of the most interested people in this field. In my opinion, one of you (Englishspeaking board members) would be the most appropriate person to write for the Bulletin, but if you wish and do not have a better idea, I can do it as well.

Regarding the letter dealing with proposals, some points you made are answered in the first part of my letter. I agree with the shift you propose, but do not suggest using the term of high technology, or we have to refuse to be more international. 'High technology' has now a political overtone so if the editorial board would like to involve more East-Europeans this term could raise some dilemmas.

Finally, I would like to close my rather long letter with the words of Le Moigne: "I congratulate you ... I shall do my best to convince, again and again, my ... colleagues and friends to put their best writings into good English!

István KISS

Hungarian Committee for Applied Systems Analysis

\section{References}

[1] J. Kindler and I. Kiss, Future methodology based on past assumptions?, in: I. Kiss and R.C. Tomlinson, eds., Rethinking the process of systems analysis (Pergamon Press, New York, 1983).

[2] Robert E.D. Woolsey, Pragmatism triumphant or past sophistication and future elegance, in: K.B. Haley, ed., OR '78 (North-Holland Publ., Amsterdam) 80-86. 